Int. J. Electrochem. Sci., 15 (2020) $7788-7795$

International Journal of

ELECTROCHEMICAL

SCIENCE

WWW.electrochemsci.org

\title{
Wettability of Nanoporous Silver Fabricated by Electrochemical Dealloying
}

\author{
Siwen Zhang, Zhiqiang Li ${ }^{*}$, Zuoxiang Qin, Qi Wang, Xing Lu* \\ Liaoning Key Materials Laboratory for Railway, School of Materials Science and Engineering, Dalian \\ Jiaotong University, Dalian 116028, People's Republic of China \\ *E-mail: lizhiqiang201@126.com (Z.L.), luxing64@163.com (X.L.)
}

doi: $10.20964 / 2020.08 .01$

Received: 3 April 2020 / Accepted: 27 May 2020 / Published: 10 July 2020

The wettability of nanoporous silver fabricated by dealloying was studied before and after stearic acid treatment. The dependencies of both water and glycerol contact angles on the variation of pore size as well as time were investigated. The research shows that nanoporous silver surfaces convert from hydrophilicity to superhydrophilicity as the pores increase from $70 \mathrm{~nm}$ to $300 \mathrm{~nm}$. After modification with stearic acid, the surfaces convert from hydrophobicity to hydrophilicity as the pores increase. The nanoporous silver surfaces exhibit lipophilicity to glycerol and become oleophobicity after modification with stearic acid. The water and glycerol contact angles both decrease from maximum to minimum values with increase of the pore size. The experiment shows that the wettability to liquid of nanoporous silver surfaces can be adjusted by pore size control and stearic acid treatment.

Keywords: nanoporous silver; dealloying; wettability; stearic acid

\section{FULL TEXT}

(C) 2020 The Authors. Published by ESG (www.electrochemsci.org). This article is an open access article distributed under the terms and conditions of the Creative Commons Attribution license (http://creativecommons.org/licenses/by/4.0/). 